\title{
Oxidative stress and ageing of the post-ovulatory oocyte
}

\author{
Tessa Lord and R John Aitken \\ School of Environmental and Life Sciences, Priority Research Centre for Reproductive Biology, \\ University of Newcastle, Callaghan, New South Wales 2308, Australia
}

Correspondence should be addressed to R J Aitken; Email: john.aitken@newcastle.edu.au

\begin{abstract}
With extended periods of time following ovulation, the metaphase II stage oocyte experiences deterioration in quality referred to as post-ovulatory oocyte ageing. Post-ovulatory ageing occurs both in vivo and in vitro and has been associated with reduced fertilization rates, poor embryo quality, post-implantation errors and abnormalities in the offspring. Although the physiological consequences of post-ovulatory oocyte ageing have largely been established, the molecular mechanisms controlling this process are not well defined. This review analyses the relationships between biochemical changes exhibited by the ageing oocyte and the symptoms associated with the ageing phenotype. We also discuss molecular events that are potentially involved in orchestrating post-ovulatory ageing with a particular focus on the role of oxidative stress. We propose that oxidative stress may act as the initiator for a cascade of events that create the aged oocyte phenotype. Specifically, oxidative stress has the capacity to cause a decline in levels of critical cell cycle factors such as maturation-promoting factor, impair calcium homoeostasis, induce mitochondrial dysfunction and directly damage multiple intracellular components of the oocyte such as lipids, proteins and DNA. Finally, this review addresses current strategies for delaying post-ovulatory oocyte ageing with a particular focus on the potential use of compounds such as caffeine or selected antioxidants in the development of more refined media for the preservation of oocyte integrity during IVF procedures.

Reproduction (2013) 146 R217-R227
\end{abstract}

\section{Introduction}

Upon release from the ovary, the prophase I oocyte undergoes a process of maturation involving resumption of meiosis, breakdown of the germinal vesicle and extrusion of the first polar body (reviewed by Sun et al. (2009)). Following maturation, the oocyte once again enters meiotic arrest, now at metaphase II (MII). The MII stage oocyte awaits fertilization by the spermatozoon either in the oviduct of the female reproductive tract or, in an assisted reproduction setting, in in vitro culture media. An optimal window exists in which fertilization of this MII stage oocyte should occur; in mammalian species, this is generally within $10 \mathrm{~h}$ of ovulation; however, successful fertilization can still occur in the mouse for up to $15 \mathrm{~h}$ (Marston \& Chang 1964, Tarin et al. 1999). In the event that no fertilization occurs within this time frame, oocytes experience a process of degradation referred to as 'post-ovulatory ageing'. It should be noted that post-ovulatory ageing is a process distinct from that of 'ovarian ageing' (reviewed by Bentov \& Casper (2013)), which occurs within the ovary of females towards the end of reproductive life, as they approach the climacteric. All references to oocyte ageing within this review refer to the deterioration of MII oocytes that occurs following their release from the ovarian follicle both in vivo and in vitro.
Post-ovulatory aged oocytes exhibit numerous aberrations in their cell biology including partial cortical granule exocytosis (Szollosi 1971, Dodson et al. 1989, Ducibella et al. 1990, Xu et al. 1997), zona hardening (Longo 1981, Dodson et al. 1989, Xu et al. 1997), a decrease in critical cell cycle factors including maturation-promoting factor (MPF) and MAPK (Kikuchi et al. 2002), mitochondrial dysfunction (Chi et al. 1988, Takahashi et al. 2003, Tatone et al. 2011, Zhang et al. 2011, Lord et al. 2013), spindle abnormalities (Wakayama et al. 2004), losses of chromosomal integrity (Spielmann et al. 1985, Mailhes et al. 1998, Wakayama et al. 2004) and epigenetic changes (Liang et al. 2008; Table 1). Not surprisingly, the process of post-ovulatory ageing culminates in apoptosis (Fujino et al. 1996) as a result of decreases in expression of the anti-apoptotic protein BCL2 (Gordo et al. 2002, Ma et al. 2005) and the activation of caspases (Takai et al. 2007, Lord et al. 2013).

The cellular deterioration associated with postovulatory ageing can strongly influence the outcome of fertilization in vivo and in vitro. This is not surprising when considering that the oocyte provides factors to the embryo that orchestrate the early events of embryogenesis (Schultz \& Heyner 1992, Minami et al. 2007), remodel the genome (Torres-Padilla et al. 2006) and repair DNA damage in both male and female nuclei 
Table 1 Aberrations to oocyte biology associated with mammalian post-ovulatory ageing.

\begin{tabular}{|c|c|c|c|}
\hline Organelle & $\begin{array}{l}\text { Consequences associated } \\
\text { with ageing }\end{array}$ & In vivo/in vitro & Reference \\
\hline Zona pellucida & Zona hardening & Both & $\begin{array}{l}\text { Longo (1981), Dodson et al. } \\
\text { (1989) and Xu et al. (1997) }\end{array}$ \\
\hline Cortical granules & Partial exocytosis & Both & $\begin{array}{l}\text { Szollosi (1971), Dodson et al. } \\
\text { (1989), Ducibella et al. } \\
\text { (1990), Xu et al. (1997) and } \\
\text { Liu et al. (2009a, 2009b) }\end{array}$ \\
\hline Spindle & Elongation, dispersal or disruption & In vitro & Wakayama et al. (2004) \\
\hline Plasma membrane & Lipid peroxidation & Both & Takahashi et al. (2003) \\
\hline \multirow[t]{2}{*}{ ER } & Depletion of $\mathrm{Ca}^{2+}$ stores & Both & Takahashi et al. (2000) \\
\hline & $\begin{array}{l}\text { Decline in } I P_{3} \text { receptor/channel } \\
\text { functionality }\end{array}$ & In vitro & Zhang et al. (2011) \\
\hline \multirow[t]{3}{*}{ Mitochondria } & Increased generation of ROS & Both & $\begin{array}{l}\text { Takahashi et al. (2003), Tatone } \\
\text { et al. (2011) and Lord et al. } \\
\text { (2013) }\end{array}$ \\
\hline & Loss of membrane potential & In vitro & Zhang et al. (2011) \\
\hline & Decreased ATP production & In vitro & Chi et al. (1988) \\
\hline \multirow[t]{3}{*}{ DNA } & Epigenetic changes & Both & Liang et al. (2008) \\
\hline & Misaligned chromosomes & Both & Wakayama et al. (2004) \\
\hline & Premature centromere separation & Both & $\begin{array}{l}\text { Spielmann et al. (1985) and } \\
\text { Mailhes et al. (1998) }\end{array}$ \\
\hline
\end{tabular}

$\mathrm{IP}_{3}$, inositol 1,4,5-trisphosphate; ROS, reactive oxygen species.

(Genesca et al. 1992). Unfortunately, the occurrence of post-ovulatory ageing is not uncommon. In the majority of mammalian species, mating occurs only at the time of ovulation, as determined by the onset of behavioural oestrus, or the act of mating itself triggers ovulation. The result of such mechanisms is that the delivery of spermatozoa to the female reproductive tract is relatively synchronized with oocyte release. In humans and certain primates, however, there are no visual signs of ovulation and, as a result, no mechanisms in place to ensure synchrony between intercourse and release of the oocyte. This, in turn, results in an increased likelihood that fertilization could involve an in vivo aged oocyte and freshly ejaculated spermatozoa. In an in vitro setting, oocytes employed in assisted reproduction technologies (ART) are often unavoidably subjected to extended periods of culture prior to fertilization. One circumstance in which this may occur is when 'rescue ICSI' is performed on failed-to-fertilize oocytes. In light of such considerations, it would clearly be beneficial to establish some control over the process of post-ovulatory oocyte ageing, particularly in an in vitro setting, where the demand for ART continues to increase exponentially (Wang et al. 2011).

This review explores the negative consequences associated with post-ovulatory oocyte ageing, discusses the poorly understood mechanisms that control this process and considers the current means by which postovulatory ageing can be prevented or delayed. Specifically, in light of recent research, we revisit the proposal that oxidative stress may act as the 'trigger' for a cascade of other events associated with oocyte ageing and hence might be an attractive approach for deterring this degenerative process in post-ovulatory oocytes.

\section{Clinical implications of oocyte ageing}

The clinical implications of oocyte ageing include a decreased capacity for fertilization both in vivo (Marston \& Chang 1964) and in vitro (Ben-Rafael et al. 1986, Badenas et al. 1989), production of poor-quality embryos (Yanagida et al. 1998, Lord et al. 2013), an increased likelihood of early pregnancy loss (Wilcox et al. 1998) and abnormalities in offspring (Tarin et al. 1999). The attributes of aged oocytes responsible for these adverse outcomes are discussed below.

\section{Decreased fertilization rate}

A decrease in fertilization rate has been associated with aged oocytes in many species including the humans (Lash \& Whittaker 1974), mice (Marston \& Chang 1964, Liu et al. 2009b), cows (Chian et al. 1992) and pigs (Kikuchi et al. 2000). This phenomenon can be attributed to multiple biochemical and functional alterations to the oocyte that accumulate with post-ovulatory age. First, aged murine oocytes are known to experience premature cortical granule exocytosis (Szollosi 1971, Dodson et al. 1989, Ducibella et al. 1990, Xu et al. 1997) and zona hardening (Longo 1981, Dodson et al. 1989, Xu et al. 1997); changes that would obviously impose limitations on the ability of the zona pellucida to interact with a spermatozoon and initiate the acrosome reaction. Additionally, as levels of lipid peroxidation are known to be elevated within post-ovulatory aged oocytes (Takahashi et al. 2003; Table 1), the fluidity of the oolemma may be decreased, reducing the likelihood of sperm-oolemma fusion and thereby fertilization.

In the event that sperm-zona interaction and spermoolemma fusion progress unimpaired, the abilities of the 
post-ovulatory aged oocyte to exhibit normal activation and initiate embryo development following fertilization are nonetheless compromised. Upon fertilization, inositol 1,4,5-trisphosphate $\left(\mathrm{IP}_{3}\right)$ receptors located on the oocyte's endoplasmic reticulum (ER) initiate calcium $\left(\mathrm{Ca}^{2+}\right)$ oscillations in response to $\mathrm{IP}_{3}$ produced by the sperm-derived factor PLC $\zeta 1$ (Yoon et al. 2008, Kuroda 2010). However, post-ovulatory aged oocytes experience a decline in $\mathrm{IP}_{3}$ receptor/channel functionality (Zhang et al. 2011), as well as suppressed ER $\mathrm{Ca}^{2+}$ ATPase activity, and exhibit a consequential depletion of $\mathrm{Ca}^{2+}$ stores that reside within the ER (Takahashi et al. 2000). As a result of this impaired $\mathrm{Ca}^{2+}$ homoeostasis, aged oocytes exhibit abnormal $\mathrm{Ca}^{2+}$ oscillations at fertilization that have significantly higher frequency and lower amplitude than those of fertilized fresh oocytes (Igarashi et al. 1997, Takahashi et al. 2003). These abnormal $\mathrm{Ca}^{2+}$ oscillations are purportedly associated with the onset of apoptosis following fertilization, rather than entry into a developmental pathway (Gordo et al. 2000, 2002).

\section{Poor embryo quality}

While the fertilization potential of post-ovulatory aged oocytes is obviously compromised, circumstances exist in which fertilization does still occur, particularly in clinical practice when ICSI is used to bypass the physiological mechanisms that would normally prevent the association of defective gametes. Not surprisingly, embryos originating from post-ovulatory aged oocytes are generally of poor quality and exhibit delayed or impaired development during subsequent embryogenesis (Yanagida et al. 1998, Lord et al. 2013).

The poor quality of these embryos is highlighted when we assess their capacity to implant in the endometrium and carry a pregnancy to term. With extensive periods of post-ovulatory ageing ( $>24 \mathrm{~h}$ in vitro), ICSI-generated embryos reportedly lose their capability for uterine implantation following embryo transfer (Chen et al. 1995). Despite this, oocytes that are subjected to shorter periods of post-ovulatory ageing can still produce embryos capable of implantation, but are prone to post-implantation errors. A clinical study assessing the effects of in vivo post-ovulatory oocyte ageing found a significant correlation between early pregnancy loss and the likelihood that delayed fertilization had occurred (Wilcox et al. 1998). These findings have also been reported in other mammalian species such as the mouse (Marston \& Chang 1964).

The decline in embryo quality associated with postovulatory aged oocytes is presumably attributed to multiple factors. First, cytoplasmic ageing is likely to greatly hinder the capacity of the oocyte to support and orchestrate embryo development, particularly when changes in both the protein and mRNA composition of the oocyte are demonstrable with prolonged ovulation to fertilization latency (Tarin et al. 2000, Hamatani et al. 2004). Additionally, aged oocytes are likely to display a corresponding increase in the proportion of non-viable embryos following fertilization as a result of chromosomal abnormalities. Post-ovulatory aged oocytes purportedly exhibit significantly higher instances of chromosome misalignment, potentially as a consequence of meiotic spindles that are elongated, dispersed or disrupted (Wakayama et al. 2004). These characteristics increase the likelihood for erroneous chromosome separation and hence aneuploidy (Mailhes et al. 1998). Further to this, in certain species such as the bovine, advancing oocyte age is also associated with a significantly increased susceptibility to polyspermy (Chian et al. 1992), which again results in the generation of embryos that are essentially non-viable.

\section{Abnormalities in offspring}

Despite the obstacles associated with fertilization of post-ovulatory aged oocytes and subsequent embryo development and implantation, birth of live offspring originating from these gametes does still occur. It was originally thought that aged oocytes that manage to support embryo development to the blastocyst stage were no less capable of producing healthy offspring than their fresh oocyte counterparts (Wilcox et al. 1998). However, more recent research has demonstrated a significant decline in live birth rates and an elevated instance of abnormalities in offspring (Tarin et al. 1999).

Tarin et al. (1999, 2002) demonstrated that offspring originating from in vivo aged oocytes exhibited growth retardation, delayed development, heightened emotional state, decreased reproductive fitness and importantly decreased longevity. Although the specific factors within the post-ovulatory aged oocyte that so prominently affect offspring integrity have not been determined, it has been hypothesized that these abnormalities may stem from the transference of a subpopulation of dysfunctional mitochondria (Tarin et al. 2002). Impaired mitochondrial function has indeed been linked with diseases such as schizophrenia (Whatley et al. 1996), Alzheimer's disease (Hutchin \& Cortopassi 1995, Budd \& Nicholls 1998) and a decreased lifespan (Sont \& Vandenbroucke 1993).

An alternative explanation for the abnormalities observed in the offspring of in vivo and in vitro aged oocytes may lay with an altered epigenetic profile, which would essentially affect gene expression in the embryo. Both the male and female genomes experience significant demethylation events following fertilization (Mayer et al. 2000) and post-ovulatory oocyte ageing has been shown to significantly alter the methylation pattern of imprinted genes in both the oocyte and the developing placenta (Liang et al. 2008, 2011). 


\section{Factors affecting oocyte ageing and apoptosis}

Post-ovulatory oocyte ageing is clearly a prominent issue affecting fecundity; however, the molecular mechanisms that control this process are not well elucidated. It is currently undetermined as to whether a single event acts to trigger a cascade of other factors, or if several biochemical and functional changes occur separately to create an 'aged', degenerating MII oocyte. Below we assess factors that are known to influence the onset of post-ovulatory ageing and specifically highlight the potential role of oxidative stress as the 'trigger' for ageing and apoptosis of the oocyte both in vitro and in vivo.

\section{Cumulus cells}

In the presence of cumulus cells, MII stage oocytes purportedly 'age' more rapidly. In vivo aged oocytes and in vitro aged oocytes enclosed within the cumulus cell complex experience increased rates of spontaneous activation and fragmentation (Miao et al. 2005, Wu et al. 2011), accelerated decline of MPF/MAPK (Miao et al. 2005) and decreased levels of blastocyst formation (Wu et al. 2011) when compared with denuded oocytes aged in vitro. Qiao et al. (2007) reported that the addition of cumulus cells to culture medium containing denuded oocytes caused an acceleration of post-ovulatory ageing on par with that of oocytes enclosed in a cumulus-oocyte complex, while other research groups have demonstrated that blocking gap junctions within the cumulus-oocyte complex does not prevent accelerated ageing (Wu et al. 2011). Following these observations, it has been hypothesized that cumulus cells secrete soluble/ paracrine factor(s) that promote post-ovulatory ageing, potentially an event that coincides with the entry of the cumulus cells into apoptosis (Wu et al. 2011). Additionally, the accelerated depletion of the oocyte metabolite pyruvate from culture medium by cumulus cells (Downs et al. 2002) appears to directly affect oocyte metabolism and hence post-ovulatory ageing, potentially by causing downstream inhibition of protein synthesis within the oocyte and upsetting redox equilibrium (Liu et al. 2009b, Li et al. 2011).

An alternative explanation for cumulus cell-associated acceleration of post-ovulatory ageing has been detailed in publications by Perez et al. (2005) and Kujjo \& Perez (2012). These researchers propose that the bioactive sphingolipid, ceramide, generated by the cumulus cells may be responsible for mitochondrial dysfunction and subsequent ageing and apoptosis in post-ovulatory oocytes. This is attributed to an increased sensitivity of aged oocytes to cytosolic ceramide spikes and the ability of ceramide to act as a pro-apoptotic factor upstream of Bax.

Although the presence of cumulus cells clearly exacerbates degeneration in ageing post-ovulatory oocytes, additional mechanisms must be at play in controlling this process, as oocytes that have been denuded of their cumulus cells also experience ageing and apoptosis (Miao et al. 2005, Lord et al. 2013).

\section{MPF and MAPK}

The critical cell cycle factors MPF and MAPK control meiotic resumption in germinal vesicle stage oocytes and then act to maintain cell cycle arrest once oocytes have reached the MII phase. A gradual decline in the concentration of these factors within the MII oocyte has been detected with post-ovulatory age and has been associated with increased levels of parthenogenetic activation and fragmentation (Kikuchi et al. 2000). The mechanism by which MPF specifically becomes degraded with post-ovulatory age has been studied extensively - particularly as a potential target for reversing the ageing process (to be discussed later in this review). MPF comprises two molecules: the catalytic subunit $\mathrm{p} 34^{\mathrm{cdc} 2}$ and the regulatory subunit cyclin B. In the active form of MPF, these two subunits are coupled and T-161 of the catalytic subunit is phosphorylated. Following fertilization, MPF is inactivated by the dephosphorylation of T-161 and degradation of the decoupled cyclin B. Interestingly, inactivation of MPF occurs via an alternate pathway in the ageing post-ovulatory oocyte. Under these circumstances, the inactive compound 'preMPF' is formed, in which the two subunits are still bound but phosphorylation of T-14 and/or T-15 of p34 ${ }^{\text {cdc2 }}$ occurs (Kikuchi et al. 2002). The accumulation of preMPF is clearly a factor controlling at least some aspects of post-ovulatory ageing as acceleration of pre-MPF formation using the tyrosine phosphatase inhibitor, vanadate, has been shown to increase susceptibility to parthenogenetic activation and fragmentation, while maintenance of active MPF levels within the oocyte using caffeine decreases levels of parthenogenesis and fragmentation (Kikuchi et al. 2002), and extends the window for fertilization (Ono et al. 2011).

\section{Mitochondrial dysfunction}

Mitochondrial dysfunction appears to be another potent mediator of the post-ovulatory oocyte ageing process. Operational mitochondria are crucial to normal oocyte function, with these organelles representing the primary source of ATP production within both oocytes and early embryos (Dumollard et al. 2007). The functionality of the mitochondria does, however, become compromised with extended periods of time following ovulation, a factor that is thought to heavily influence oocyte quality. Diminished mitochondrial integrity in the in vitro aged oocyte has been demonstrated by a loss of mitochondrial membrane potential (Zhang et al. 2011) and a decline in levels of ATP production (Chi et al. 1988).

As damage to the mitochondria is known to cause an increased production of reactive oxygen species (ROS) 
and the release of pro-apoptotic factors such as cytochrome $c$ (Liu et al. 2009a), which recruit members of apoptotic machinery such as caspases (Takai et al. 2007) and endonucleases (Fujino et al. 1996), it is likely that mitochondrial dysfunction is the link between postovulatory oocyte ageing and apoptosis. Additionally, loss of mitochondrial integrity can result in aberrant protein synthesis and inactivation or loss of mitochondrial DNA (mtDNA; reviewed by Shigenaga et al. (1994)).

The pronounced control that mitochondrial function has over post-ovulatory ageing has been demonstrated in studies utilizing microinjection of isolated mitochondria into in vitro aged oocytes. During a 24-h culture period, MII oocytes whose mitochondrial pool was increased by $5 \%$ via microinjection showed a significant decline in levels of programmed cell death when compared with control oocytes (Perez et al. 2000).

\section{Oxidative stress: the initiator of post-ovulatory ageing?}

It has been demonstrated by several research groups that ROS - particularly hydrogen peroxide $\left(\mathrm{H}_{2} \mathrm{O}_{2}\right)$, superoxide anion $\left(\mathrm{O}_{2} \cdot{ }^{-}\right)$and peroxynitrite $\left(\mathrm{ONOO}^{-}\right)^{-}$ accumulate in oocytes with increasing amounts of time following ovulation both in vitro and in vivo (Takahashi et al. 2003, Tatone et al. 2011, Lord et al. 2013). ROS production within the MII oocyte likely occurs as a by-product of oxidative phosphorylation; however, environmental factors that oocytes are subjected to in vitro (exposure to light, lack of antioxidant rich follicular and tubal fluids and increased oxygen tension) are also thought to facilitate ROS production (Mastroianni \& Jones 1965, Mass et al. 1976, Goto et al. 1993, Guerin et al. 2001). While the oocyte does offer some intracellular defence against oxidative attack in the form of the antioxidant glutathione, these resources are depleted with post-ovulatory age (Boerjan \& de Boer 1990, Yoshida et al. 1993). As a consequence of the progressive increase in ROS production and the concomitant depletion of antioxidant protection, the post-ovulatory aged oocyte experiences a state of oxidative stress. We hypothesize that this oxidative stress may act as the 'trigger' for a cascade of other factors that orchestrate post-ovulatory ageing, as well as directly affect multiple aspects of oocyte biochemistry and functionality. The idea that oxidative stress may be the initiator of ageing in the MII oocyte is supported by recent findings indicating that the onset of oxidative stress is a relatively early event in in vitro culture (Lord et al. 2013). Indeed, links can be established between oxidative stress in the oocyte and the aforementioned decline in critical cell cycle factors, mitochondrial dysfunction, apoptosis, impaired $\mathrm{Ca}^{2+}$ homoeostasis, decreased fertilization rate, poor embryo quality and abnormalities in offspring. These associations will be discussed below.

We propose that the decline in the critical cell cycle factor, MPF, which reportedly orchestrates some facets of post-ovulatory ageing, may be a symptom of oxidative stress in the MII oocyte. As mentioned previously, the accumulation of 'pre-MPF' occurs with increasing periods following ovulation, with phosphorylation at multiple sites on the catalytic subunit of MPF effectively inactivating this compound (Kikuchi et al. 2000, 2002). The enzymes that purportedly control these phosphorylation events are cdc25 (a tyrosine phosphatase) and Wee1/Myt1 (tyrosine kinases) (Kikuchi et al. 2002). Interestingly, ROS have previously been shown to have a capacity for both inhibition of tyrosine phosphatases (Monteiro et al. 1991, Sullivan et al. 1994), including cdc25 specifically (Brisson et al. 2007), and stimulation of tyrosine kinases (Chan et al. 1986). As a result, the induction of oxidative stress in the post-ovulatory oocyte may directly affect levels of MPF within the cell, resulting in the onset of associated downstream symptoms of oocyte ageing such as parthenogenesis and fragmentation (Kikuchi et al. 2002).

Oxidative stress that occurs with post-ovulatory age also has the potential to directly affect mitochondrial function. The DNA, proteins and lipids within the mitochondria are particularly susceptible to oxidative attack, not only because of their close proximity to the source of ROS production (the electron transport chain (ETC)) but also in the case of mtDNA, because of the absence of protective histones and mechanisms for DNA repair (reviewed by Shigenaga et al. (1994)). Oxidative stress has been linked with mtDNA damage and deletions (Sohal \& Dubey 1994), loss of mitochondrial membrane potential (Liu et al. 2000), increased ROS generation by the ETC (Liu et al. 2009a) and a decline in ATP production (Melov et al. 1999). Importantly, factors such as increased ROS generation and a decline of ATP production are also known to be associated with postovulatory ageing (Chi et al. 1988, Lord et al. 2013), suggesting that a link between oxidative stress and agerelated mitochondrial dysfunction is certainly plausible. Notably, oxidative damage to mtDNA in the oocyte could potentially be the basis for the aforementioned abnormalities associated with impaired mitochondrial function in offspring originating from aged oocytes (Tarin et al. 2002).

Oxidative stress also has the capacity to directly influence the onset of apoptosis in post-ovulatory aged oocytes. $\mathrm{H}_{2} \mathrm{O}_{2}$ treatment of MII oocytes in vitro has been shown to cause a decline in levels of the anti-apoptotic molecule Bcl-2 (Takahashi et al. 2009), induce expression of pro-apoptotic Bax and caspase-3, and precipitate both DNA fragmentation (Chaube et al. 2007) and cytochrome c release (Liu et al. 2000). Importantly, these pathologies are common to both oxidative stress and oocyte ageing, and relief from oxidative stress by way of antioxidant treatment has been shown to delay the onset of fragmentation and caspase activation associated with post-ovulatory ageing (Lord et al. 2013). 
In addition to potentially being a precursor to MPF/MAPK depletion, mitochondrial dysfunction and subsequent apoptosis, the damaging nature of oxidative stress itself is likely to be directly involved in generation of the 'aged oocyte' phenotype. First, oxidative stress may be accountable for a perturbation of $\mathrm{Ca}^{2+}$ homoeostasis in aged oocytes. Previous research has demonstrated that these two events are implicitly linked, as treatment of fresh oocytes with $\mathrm{H}_{2} \mathrm{O}_{2}$ results in abnormal $\mathrm{Ca}^{2+}$ oscillations following fertilization, which exhibit similar frequency and amplitude to those produced by post-ovulatory aged oocytes (Igarashi et al. 1997, Takahashi et al. 2003). The basis for this interaction lies with the capacity for ROS to directly affect the $\mathrm{Ca}^{2+}$ channels and $\mathrm{Ca}^{2+}$-ATPases of the ER (Rohn et al. 1993, Doan et al. 1994, Wesson \& Elliot 1995), as well as the $\mathrm{Ca}^{2+}$ signalling molecule calmodulin (Gao et al. 2001). Further facets of oocyte biochemistry have also been shown to be vulnerable to oxidative attack; specifically zona pellucida dissolution time and cortical granule loss; which are significantly altered following treatment with $\mathrm{H}_{2} \mathrm{O}_{2}$ and $\mathrm{O}_{2}{ }^{-}{ }^{-}$(Goud et al. 2008a). The mechanisms behind these pathologies remain elusive, although it is plausible that oxidative stress influences processes under the control of cytoskeletal fibres, such as cortical granule exocytosis and polar body extrusion, by generating damage to the mitochondria that results in decreased ATP production (Chi et al. 1988). With decreased ATP availability, the dynamics of actin and tubulin assembly-disassembly would likely be impeded (Bershadsky et al. 1980).

Finally, oxidative stress is also capable of generating global damage to lipid, protein and DNA constituents of the cell (reviewed by Guerin et al. (2001)). As previously mentioned, peroxidation to lipids in the plasma membrane may decrease the oocyte's potential for sperm-oocyte fusion. Additionally, such global acquisition of oxidative damage in aged oocytes is presumably related to poor embryo quality following fertilization, as relief from oxidative stress in the aged MII oocyte has been linked with improved developmental potential (Lord et al. 2013).

In conclusion, we propose that the development of oxidative stress is a relatively early event following ovulation that may initiate a decline in MPF levels, generate mitochondrial damage resulting in apoptosis, perturb $\mathrm{Ca}^{2+}$ homoeostasis and instigate damage to the lipid, protein and DNA components of the cell, as well as to the cytoskeleton and zona pellucida. The acquisition of such oxidative damage post-ovulation may culminate in the observed reduction in fertilization rate, decline in embryo quality and increased likelihood for abnormalities in offspring associated with the aged oocyte (Fig. 1). If oxidative stress is indeed the instigator for postovulatory degeneration of the MII oocyte, it would be interesting to establish whether the biochemical changes that occur within the oocyte following timely fertilization (i.e. prior to the onset of 'ageing') involve increased expression of antioxidant enzymes or enzymes involved in repair of oxidative damage. Certainly, recent research within our laboratory suggests an increased capacity to cope with oxidative insult in oocytes post-fertilization (T Lord and R J Aitken (2013), unpublished observations).

\section{Mechanisms for preventing/delaying oocyte ageing}

The final portion of this review looks into current strategies for delaying or preventing post-ovulatory oocyte ageing and assesses their effectiveness and potential for adaptation to clinical use in the future.

\section{Culture conditions and media composition}

Alterations to the concentration of metabolites within oocyte culture media has been shown to prominently affect post-ovulatory ageing in vitro. Specifically, increasing the concentration of pyruvate within culture media has been shown to delay post-ovulatory ageing by maintaining cortical granule integrity, decreasing susceptibility to activating stimuli, preventing an ageassociated decline in levels of MPF and glutathione, improving blastocyst formation rates following fertilization and delaying the onset of apoptosis (Liu et al. 2009b, $\mathrm{Li}$ et al. 2012). As the oocyte and early embryo preferentially utilize pyruvate over glucose to drive metabolism (Leese \& Barton 1984), it has been proposed that pyruvate supplementation delays oocyte ageing by fuelling prolonged ATP production within oocytes and also by maintaining intracellular redox potential (Liu et al. 2009b, Li et al. 2011). Increased pyruvate concentration is particularly effective in preventing accelerated in vitro ageing of the cumulus-enclosed MII oocyte, a result likely attributed to the more rapid depletion of pyruvate from culture media in the presence of cumulus cells (Downs et al. 2002).

Alteration of culture temperature has also been shown to delay the onset of post-ovulatory ageing in vitro. Porcine oocytes supplemented with pyruvate and stored at $15{ }^{\circ} \mathrm{C}$ were able to be successfully fertilized and maintain developmental potential after $42 \mathrm{~h}$ in vitro, whereas oocytes exposed to the same conditions at $37^{\circ} \mathrm{C}$ could only be successfully fertilized after $6 \mathrm{~h}$ of culture (Li et al. 2012). The mechanism behind delayed ageing at low temperatures is likely related to a down-regulation of oocyte metabolism (Chip et al. 2011), resulting in reduced levels of ROS production and, subsequently, a decreased likelihood for oxidative damage and ROS-induced apoptosis (Li et al. 2012).

\section{Maintenance of MPF levels}

Currently, one of the most thoroughly investigated methods for preventing/delaying post-ovulatory oocyte 


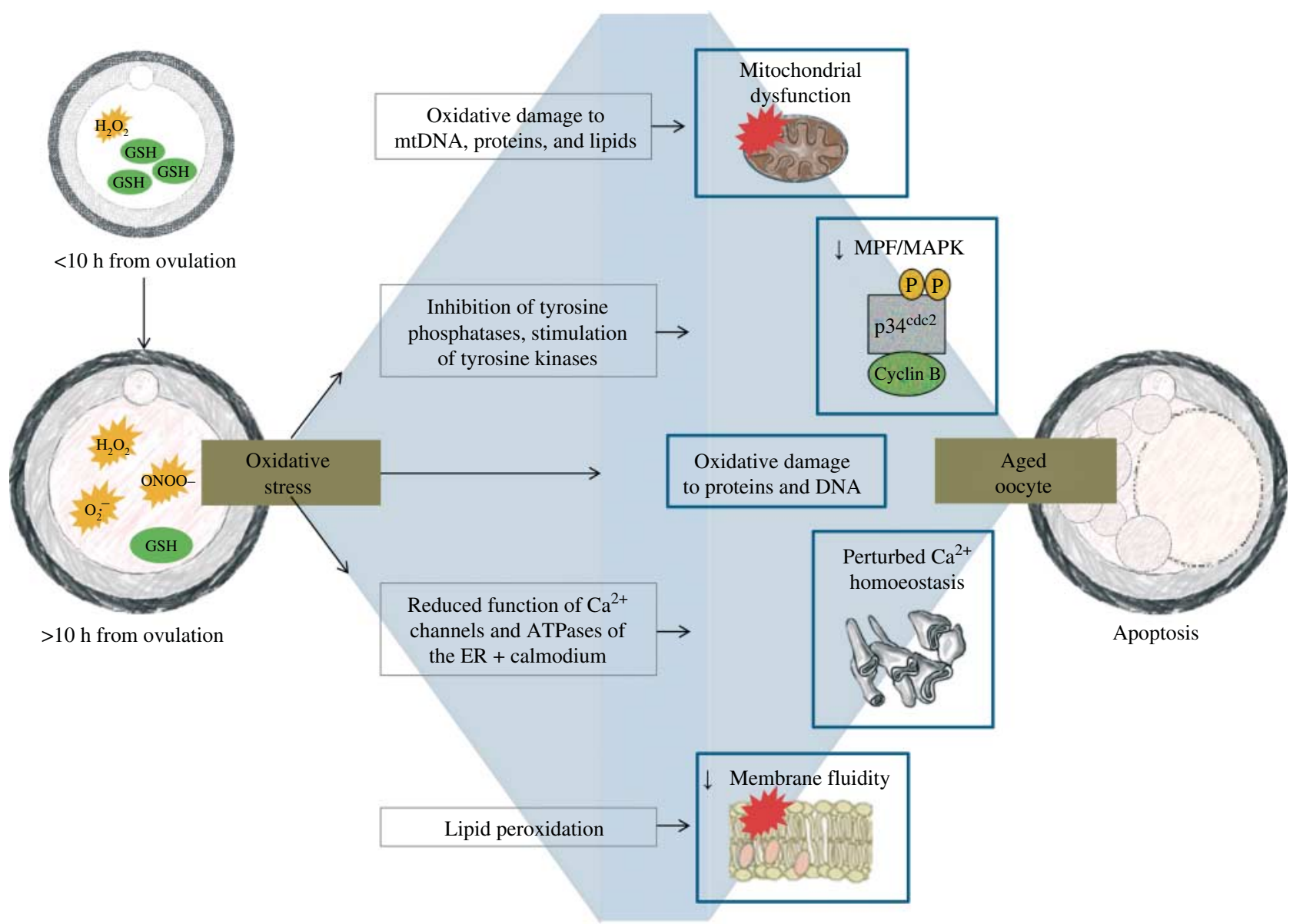

Figure 1 With increasing amounts of time following ovulation, MIl stage oocytes experience an accumulation of ROS and a depletion of GSH resulting in the onset of oxidative stress. Oxidative stress has the potential to initiate the post-ovulatory ageing process via multiple pathways: i) through oxidative damage to the mitochondria resulting in subsequent dysfunction, ii) through inhibition of tyrosine phosphatases and stimulation of tyrosine kinases resulting in a decline in levels of MPF, iii) by causing global damage to proteins and DNA, iv) by reducing the function of $\mathrm{Ca}^{2+}$ channels and ATPases in the ER as well as affecting the $\mathrm{Ca}^{2+}$ signalling molecule calmodulin resulting in perturbed $\mathrm{Ca}^{2+}$ homoeostasis and v) through peroxidation of lipids in the plasma membrane, decreasing membrane fluidity and potentially affecting the oocytes' potential for fusion with the spermatozoon. The accumulation of these factors, potentially as a result of oxidative stress, results in the culmination of an 'aged' oocyte.

ageing in vitro is by maintaining levels of critical cell cycle factors within the cell. Caffeine is one such compound that has been utilized in this regard, as it acts to inhibit phosphorylation of MPF to pre-MPF by Wee1/Myt1. Supplementation of oocyte culture media with caffeine has indeed been shown to maintain levels of MPF post-ovulation and to subsequently decrease levels of parthenogenesis and fragmentation (Kikuchi et al. 2002). Additionally, recent studies have established that the addition of caffeine or MG132 (a proteasome inhibitor) to oocyte culture can increase fertilization rates by ICSI and decrease fragmentation in embryos (Ono et al. 2011). Further modes of action for caffeine in relation to postovulatory ageing include a delay in the deterioration of $\mathrm{Ca}^{2+}$ release mechanisms, although the underlying pharmacology is not yet clear (Zhang et al. 2011).

While live offspring have been obtained using oocytes that were exposed to caffeine treatment (Ono et al. 2011), previously published research has implicated caffeine as an inhibitor of DNA repair mechanisms (Selby \& Sancar 1990). This impairment of DNA repair has been demonstrated to directly affect oocytes, as caffeine-treated golden hamster eggs lost their capacity to repair aberrations in both chromatids and chromosomes following fertilization by spermatozoa possessing DNA damage (Genesca et al. 1992). This clearly creates concern as to the safety of utilizing caffeine as an agent for preventing post-ovulatory oocyte ageing in vitro, as un-repaired DNA damage within the embryo may result in abnormalities/birth defects in offspring.

In a similar fashion to caffeine, MG132 has also been demonstrated to maintain high MPF levels in oocytes in vitro, by preventing degradation of cyclin B. Oocytes treated with MG132 have been shown to produce embryos with improved developmental potential; however, the capacity to produce live offspring is reduced (Yu et al. 2005), potentially as a result of inhibition of necessary protein degradation (Gao et al. 2005). Again, 
MG132 is clearly not a suitable compound for utilization in an ART setting.

In addition to the aforementioned impacts of caffeine or MG132 on cultured oocytes, recent research has suggested that not all facets of post-ovulatory ageing can be controlled by manipulation of cell cycle factors. It has been demonstrated that caffeine-supplemented oocytes do not experience any delay in the onset of ageassociated apoptosis, nor any relief from accumulation of oxidative stress (Lord et al. 2013). If accumulation of oxidative stress is indeed an upstream event that is intricately linked with age-associated declines in critical cell cycle factors, then relief from oxidative stress by way of antioxidant supplementation should maintain MPF/MAPK levels in vitro.

\section{Antioxidants}

If oxidative stress acts as a 'trigger' for ageing in postovulatory oocytes, then it would be expected that antioxidant treatment would effectively delay this process, either via supplementation of oocyte culture medium to delay ageing in vitro or by oral administration to prevent ageing of oocytes in vivo.

In vitro studies have indeed demonstrated that antioxidant supplementation can attenuate the process of post-ovulatory oocyte ageing; however, this phenomenon is reliant on the type of antioxidant utilized. Early research by Tarin et al. (1998) demonstrated that L-ascorbic acid (vitamin C) and 6-methoxy-2,5,7,8tetramethylchlormane-2-carboxylic acid (trolox/vitamin E) could not significantly improve fertilization rate nor prevent fragmentation associated with post-ovulatory ageing, while $\beta$-mercaptoethanol and L-cysteine in fact decreased the likelihood of aged oocytes reaching the blastocyst stage following fertilization. However, this research also established that addition of the reducing agent dithiothreitol (DTT) to oocyte culture medium resulted in increased fertilization and blastocyst formation rates, potentially by protecting free thiol groups within these 'ageing' oocytes from becoming oxidized. Despite the reported benefits associated with DTT, the application of this method for delaying post-ovulatory ageing in a clinical setting is limited as DTT has been associated with DNA damage within cells (Held et al. 1996, Oikawa et al. 2002).

Treatment of oocytes with the nitric oxide $(\mathrm{NO} \cdot)$ donor S-nitroso- $\mathrm{N}$-acetylpenicillamine has also been shown to attenuate certain signs associated with postovulatory ageing such as cortical granule exocytosis, zona hardening and poor embryo quality (Goud et al. 2008b). NO has been identified in multiple studies as a free radical crucial to oocyte and embryo function (Gouge et al. 1998, Kuo et al. 2000). NO• does exhibit antioxidant characteristics - specifically a capacity to scavenge $\mathrm{O}_{2} \cdot{ }^{-}$(Robak \& Grygleweski 1993); however, the exact mechanism by which NO elicits its age-attenuating effects remains elusive.

More recently, a study conducted by our laboratory (Lord et al. 2013) has identified that the potent antioxidant melatonin provides protection from postovulatory ageing when used to supplement in vitro culture medium. Oocytes treated with melatonin experienced a delayed onset of apoptosis, decreased levels of fragmentation, an increased optimal window for fertilization and improved embryo quality when compared with control aged oocyte counterparts. These effects are presumably a direct result of relief from oxidative stress, as melatonin-treated aged oocytes exhibited significantly reduced levels of ROS (Lord et al. 2013). Further to this, previous studies have highlighted the ability of melatonin to reverse the deleterious effects of $\mathrm{H}_{2} \mathrm{O}_{2}$ treatment on MII oocytes (Tamura et al. 2008) and prevent hypochlorous acid-induced abnormalities in chromosomes and microtubules (Banerjee et al. 2012). Importantly, melatonin has a lack of demonstrable toxicity (Jahnke et al. 1999), making it a primary candidate for utilization in an assisted reproduction setting.

Although the ability of antioxidants to influence postovulatory ageing is well characterized in vitro, the capacity for these compounds to delay in vivo ageing is poorly defined. Oral administration of antioxidants such as co-enzyme Q10, melatonin and N-acetyl-L-cysteine has been linked with improved oocyte quality, as well as increased fertilization rates and litter sizes in clinical and laboratory studies (Tamura et al. 2008, Burstein et al. 2009, Liu et al. 2012); however, these reports focus primarily on the relationship between antioxidants and ovarian ageing. To the authors' knowledge, no in vivo studies have been conducted to establish the effects of orally administered antioxidants on post-ovulatory ageing specifically.

Although the beneficial effects of antioxidants on postovulatory oocyte ageing are dependent on the antioxidant utilized, these compounds may be at the forefront in terms of delaying in vitro ageing prior to IVF or ICSI, particularly if oxidative stress does act as the 'trigger' for downstream pathological changes. The variation in therapeutic potential between antioxidants trialled to date may be attributed to the different reactive species scavenged by each compound, their stability in in vitro culture media, their capacity to infiltrate multiple organelles within the cell and also their potency at concentrations that are considered safe for clinical use. Following the success of antioxidant supplementation in vitro, it would be beneficial to establish the capability of these compounds to delay the onset of senescence in MII oocytes in vivo.

\section{Concluding remarks}

Ageing of post-ovulatory oocytes clearly has a major impact on fertilization potential, the quality of resulting 
embryos, the likelihood of carrying a pregnancy to term and the health and well-being of offspring. Although factors such as MPF/MAPK decline and mitochondrial dysfunction are known to be involved in orchestrating post-ovulatory ageing, the exact molecular mechanisms that control these processes remain elusive. This review has proposed that oxidative stress may act as the 'initiator' of a chain of events that create the aged oocyte phenotype. Oxidative stress can be directly linked not only with MPF decline and mitochondrial dysfunction but also with the acquisition of many abnormalities in oocyte biology such as aberrant $\mathrm{Ca}^{2+}$ homoeostasis and damage to proteins, lipids and DNA. We have proposed that relieving oxidative stress using antioxidant supplementation may provide a safe and effective avenue for delaying post-ovulatory ageing, specifically in an assisted reproduction setting where extended periods of time between ovulation and fertilization may be unavoidable.

\section{Declaration of interest}

The authors declare that there is no conflict of interest that could be perceived as prejudicing the impartiality of the review.

\section{Funding}

The research underlining this review was funded by grants from the National Health and Medical Research Council of Australia and the Australian Research Council to R J Aitken. T Lord is the recipient of an Australian Postgraduate Award PhD scholarship.

\section{References}

Badenas J, Santalo J, Calafell JM, Estop AM \& Eqozcue J 1989 Effect of the degree of maturation of mouse oocytes at fertilization: a source of chromosome imbalance. Gamete Research 24 205-218. (doi:10.1002/ mrd.1120240208)

Banerjee J, Maitra D, Diamond MP \& Abu-Soud HM 2012 Melatonin prevents hypochlorous acid-induced alterations in microtubule and chromosomal structure in metaphase-II mouse oocytes. Journal of Pineal Research 53 122-128. (doi:10.1111/j.1600-079X.2012.00977.x)

Ben-Rafael Z, Kopf GS, Blasco L, Tureck RW \& Mastroianni LJ 1986 Fertilization and cleavage after reinsemination of human oocytes in vitro. Fertility and Sterility 45 58-62.

Bentov Y \& Casper RF 2013 The aging oocyte - can mitochondrial function be improved? Fertility and Sterility 99 18-22. (doi:10.1016/j.fertnstert. 2012.11.031)

Bershadsky AD, Gelfand VI, Svitkina TM \& Tint IS 1980 Destruction of microfilament bundles in mouse embryo fibroblasts treated with inhibitors of energy metabolism. Experimental Cell Research 127 421-429. (doi:10.1016/0014-4827(80)90446-2)

Boerjan ML \& de Boer P 1990 First cell cycle of zygotes of the mouse derived from oocytes aged postovulation in vivo and fertilized in vivo. Molecular Reproduction and Development 25 155-163. (doi:10.1002/ mrd.1080250208)

Brisson M, Foster C, Wipf P, Joo B, Tomko RJJ, Nguyen T \& Lazo JS 2007 Independent mechanistic inhibition of cdc25 phosphatases by natural product caulibugulone. Molecular Pharmacology 71 184-192. (doi:10.1124/mol.106.028589)
Budd SL \& Nicholls DG 1998 Mitochondria in the life and death of neurons. Essays in Biochemistry 33 43-52.

Burstein E, Perumalsamy A, Bentov Y, Esfandiari N, Jurisicova A \& Casper RF 2009 Co-enzyme Q10 supplementation improves ovarian response and mitochondrial function in aged mice. Fertility and Sterility 92 S31. (doi:10.1016/j.fertnstert.2009.07.121)

Chan TM, Chen E, Tatoyan A, Shargill NS, Pleta M \& Hochstein P 1986 Stimulation of tyrosine-specific protein phophorylation in the rat liver plasma membrane by oxygen radicals. Biochemical and Biophysical Research Communications 139 439-445. (doi:10.1016/S0006-291X (86)80010-9)

Chaube SK, Prasad PV, Thakur SC \& Shirastav TG 2007 Hydrogen peroxide modulates meiotic cell cycle and induces morphological features characteristic of apoptosis in rat oocytes cultured in vitro. Apoptosis $\mathbf{1 0}$ 863-874. (doi:10.1007/s10495-005-0367-8)

Chen HL, Copperman AB, Grunfeld L, Sandler B, Bustillo M \& Gordon JW 1995 Failed fertilization in vitro: second day micromanipulation of oocytes versus reinsemination. Fertility and Sterility 63 1337-1340.

Chi M, Manchester JK, Yang VC, Curato AD, Strickler RC \& Lowry OH 1988 Contrast in levels of metabolic enzymes in human and mouse ova. Biology of Reproduction 39 295-307. (doi:10.1095/biolreprod39. 2.295)

Chian RC, Nakahara H, Niwa K \& Funahashi H 1992 Fertilization and early cleavage in vitro of ageing bovine oocytes after maturation in culture. Theriogenology 37 665-672. (doi:10.1016/0093-691X(92)90146-I)

Chip S, Zelmer A, Ogunshola OO, Felderhoff-Mueser U, Nitsch C, Buhrer C \& Wellmann S 2011 The RNA-binding protein RBM3 is involved in hypothermia induced neuroprotection. Neurobiological Disorders 43 388-396. (doi:10.1016/j.nbd.2011.04.010)

Doan TN, Gentry DL, Taylor AA \& Elliot SJ 1994 Hydrogen peroxide activates agonist-sensitive $\mathrm{Ca}^{2+}$-flux pathways in canine venous endothelial cells. Biochemical Journal 297 209-215.

Dodson MG, Minhas BS, Curtis SK, Palmer TV \& Robertson JL 1989 Spontaneous zona reaction in the mouse as a limiting factor for the time in which an oocyte may be fertilized. Journal of In Vitro Fertilization and Embryo Transfer 6 101-106. (doi:10.1007/BF01130735)

Downs SM, Humpherson PG \& Leese HJ 2002 Pyruvate utilization by mouse oocytes is influenced by meiotic status and the cumulus oophorus. Molecular Reproduction and Development 62 113-123. (doi:10.1002/mrd.10067)

Ducibella T, Duffy P, Reindollar R \& Su B 1990 Changes in the distribution of mouse oocyte cortical granules and ability to undergo the cortical reaction during gonadotropin-stimulated meiotic maturation and aging in vivo. Biology of Reproduction 43 870-876. (doi:10.1095/biolreprod43.5.870)

Dumollard R, Ward Z, Carroll J \& Duchen MR 2007 Regulation of redox metabolism in the mouse oocyte and early embryo. Development $\mathbf{1 3 4}$ 455-465. (doi:10.1242/dev.02744)

Fujino Y, Ozaki K, Yamamasu S, Ito F, Matsuoka I, Hayashi E, Nakamura H, Ogita S, Sato E \& Inoue M 1996 DNA fragmentation of oocytes in aged mice. Human Reproduction 11 1480-1483. (doi:10.1093/oxfordjournals.humrep.a019421)

Gao J, Yao Y \& Squier TC 2001 Oxidatively modified calmodulin binds to the plasma membrane Ca-ATPase in a nonproductive and conformationally disordered complex. Biophysical Journal 80 1791-1801. (doi:10.1016/S0006-3495(01)76149-8)

Gao S, Zhiming H, Kihara M, Adashi E \& Latham KE 2005 Protease inhibitor MG132 in cloning: no end to the nightmare. Trends in Biotechnology 23 66-68. (doi:10.1016/j.tibtech.2004.12.007)

Genesca A, Caballin MR, Miro R, Benet J, Germa JR \& Egozcue J 1992 Repair of human sperm chromosome aberrations in the hamster egg. Human Genetics 89 181-186. (doi:10.1007/BF00217120)

Gordo AC, Wu H, He CL \& Fissore RA 2000 Injection of sperm cyosolic factor into mouse metaphase II oocytes induces different developmental fates according to the frequency of $\left[\mathrm{Ca}^{2+}\right]$ oscillations and oocyte age. Biology of Reproduction 62 1370-1379. (doi:10.1095/biolreprod62.5. 1370)

Gordo AC, Rodrigues P, Kurokawa M, Jellerette T, Exley GE, Warner C \& Fissore RA 2002 Intracellular calcium oscillations signal apoptosis rather than activation in in vitro aged mouse eggs. Biology of Reproduction $\mathbf{6 6}$ 1828-1837. (doi:10.1095/biolreprod66.6.1828) 
Goto K, Noda Y, Mori T \& Nakano M 1993 Increased generation of reactive oxygen species in embryos cultured in vitro. Free Radical Biology \& Medicine 15 69-75. (doi:10.1016/0891-5849(93)90126-F)

Goud AP, Goud PT, Diamond MP, Gonik B \& Abu-Soud HM 2008a Reactive oxygen species and oocyte aging: role of superoxide, hydrogen peroxide and hypochlorous acid. Free Radical Biology \& Medicine 44 1295-1304. (doi:10.1016/j.freeradbiomed.2007.11.014)

Goud PT, Goud AP, Diamond MP, Gonik B \& Abu-Soud HM 2008b Nitric oxide extends the oocyte temporal window for optimal fertilization. Free Radical Biology \& Medicine 45 453-459. (doi:10.1016/j.freeradbiomed. 2008.04.035)

Gouge RC, Marshburn P, Gordon BE, Nunley W \& Huet-Hudson YM 1998 Nitric oxide as a regulator for embryonic development. Biology of Reproduction 58 875-879. (doi:10.1095/biolreprod58.4.875)

Guerin P, Mouatassim SE \& Menezo Y 2001 Oxidative stress and protection against reactive oxygen species in the pre-implantation embryo and its surroundings. Human Reproduction Update 7 175-189. (doi:10.1093/ humupd/7.2.175)

Hamatani T, Falco G, Carter MG, Akutsu H, Stagg CA, Sharov AA, Dudekula DB, VanBuren V \& Ko MSH 2004 Age-associated alteration of gene expression patterns in mouse oocytes. Human Molecular Genetics 13 2263-2278. (doi:10.1093/hmg/ddh241)

Held KD, Sylvester C, Hopcia KL \& Biaglow JE 1996 Role of fenton chemistry in thiol-induced toxicity and apoptosis. Radiation Research 145 542-553. (doi:10.2307/3579272)

Hutchin T \& Cortopassi G 1995 A mitochondrial DNA clone is associated with increased risk for Alzheimer disease. PNAS 92 6892-6895. (doi:10.1073/pnas.92.15.6892)

Igarashi H, Takahashi E, Hiroi M \& Doi K 1997 Aging related changes in calcium oscillations in fertilized mouse oocytes. Molecular Reproduction and Development 48 383-390. (doi:10.1002/(SICI)1098-2795 (199711)48:3<383::AID-MRD12>3.0.CO;2-X)

Jahnke G, Marr M, Myers C, Wilson R, Travlos C \& Price C 1999 Maternal and developmental toxicity evaluation of melatonin administration orally to pregnant Sprague-Dawley rats. Toxicological Sciences $\mathbf{5 0}$ 271-279. (doi:10.1093/toxsci/50.2.271)

Kikuchi K, Naito K, Noguchi J, Shimada A, Kaneko H, Yamashita M, Aoki F, Tojo H \& Toyoda Y 2000 Maturation/M-phase promoting factor: a regulator of aging in porcine oocytes. Biology of Reproduction $\mathbf{6 3}$ 715-722. (doi:10.1095/biolreprod63.3.715)

Kikuchi K, Naito K, Noguchi J, Kaneko H \& Tojo H 2002 Maturation/M-phase promoting factor regulates aging of porcine oocytes matured in vitro. Cloning and Stem Cells 4 211-222. (doi:10.1089/15362300260339494)

Kujjo LL \& Perez GI 2012 Ceramide and mitochondrial function in aging oocytes: joggling a new hypothesis and old players. Reproduction 143 1-10. (doi:10.1530/REP-11-0350)

Kuo RC, Baxter GT, Thompson SH, Stricker SA, Patton C, Bonaventura J \& Epel D $2000 \mathrm{NO}$ is necessary and sufficient for egg activation at fertilization. Nature 406 633-636. (doi:10.1038/35020577)

Kuroda K 2010 Sperm factor, PLC zeta, and egg activation. Journal of Mammalian Ova Research 27 198-203. (doi:10.1274/jmor.27.198)

Lash J \& Whittaker JR 1974. Concepts of development. In Fertilization. Series editor: C R Austin Publisher: Sinauer Associates Inc.

Leese HJ \& Barton AM 1984 Pyruvate and glucose uptake by mouse ova and preimplantation embryos. Journal of Reproduction and Fertility 72 9-13. (doi:10.1530/jrf.0.0720009)

Li Q, Miao D, Zhou P, Wu Y, Gao D, Wei D, Cui W \& Tan J 2011 Glucose metabolism in mouse cumulus cells prevents oocyte aging by maintaining both energy supply and the intracellular redox potential. Biology of Reproduction 84 1111-1118. (doi:10.1095/biolreprod.110.089557)

Li Q, Wang G, Zhang J, Zhou P, Wang T, Cui W, Luo M \& Tan J 2012 Combined inhibitory effects of pyruvate and low temperature on postovulatory aging of mouse oocytes. Biology of Reproduction 87 105. (doi:10.1095/biolreprod.112.103127)

Liang XW, Zhu JQ, Miao Y, Liu J, Wei L, Lu S, Hou Y, Schatten H, Lu K \& Sun Q 2008 Loss of methylation imprint of Snrpn in postovulatory aging mouse oocyte. Biochemical and Biophysical Research Communications 371 16-21. (doi:10.1016/j.bbrc.2008.03.105)

Liang XW, Ge ZI, Wei L, Guo L, Han ZM, Schatten H \& Sun QY 2011 The effects of postovulatory aging of mouse oocytes on methylation and expression of imprinted genes at mid-term gestation. Molecular Human Reproduction 17 562-567. (doi:10.1093/molehr/gar018)
Liu L, Trimarchi JR \& Keefe DL 2000 Involvement of mitochondria in oxidative stress-induced cell death in mouse zygotes. Biology of Reproduction 62 1745-1753. (doi:10.1095/biolreprod62.6.1745)

Liu H, Wang T \& Huang K 2009a Cholestane-3B, 5a, 6B-triol-induced reactive oxygen species production promotes mitochondrial dysfunction in isolated mice liver mitochondria. Chemico-Biological Interactions 179 81-87. (doi:10.1016/j.cbi.2008.12.003)

Liu N, Wu Y, Lan G, Sui H, Ge L, Wang J, Liu Y, Qiao T \& Tan J 2009b Pyruvate prevents aging of mouse oocytes. Reproduction 138 223-234. (doi:10.1530/REP-09-0122)

Liu J, Liu M, Ye X, Liu K, Huang J, Wang L, Ji G, Liu N, Tang X, Baltz JM et al. 2012 Delay in oocyte ageing in mice by the antioxidant $\mathrm{N}$-acetyl-Lcysteine (NAC). Human Reproduction 27 1411-1420. (doi:10.1093/ humrep/des019)

Longo FJ 1981 Changes in the zones pellucidae and plasmalemma of aging mouse eggs. Biology of Reproduction 25 399-411. (doi:10.1095/ biolreprod25.2.399)

Lord T, Nixon B, Jones KT \& Aitken RJ 2013 Melatonin prevents postovulatory oocyte aging in the mouse and extends the window for optimal fertilization in vitro. Biology of Reproduction 88 1-9. (doi:10.1095/ biolreprod.112.106450)

Ma W, Zhang D, Hou Y, Li Y, Sun Q, Sun X \& Wang W 2005 Reduced expression of MAD2, BCL2, and MAP kinase activity in pig oocytes after in vitro aging are associated with defects in sister chromatid segregation during meiosis II and embryo fragmentation after activation. Biology of Reproduction 72 373-383. (doi:10.1095/biolreprod.104. 030999)

Mailhes JB, Young D \& London SN 1998 Postovulatory ageing of mouse oocytes in vivo and premature centromere separation and aneuploidy. Biology of Reproduction 58 1206-1210. (doi:10.1095/biolreprod58.5. 1206)

Marston JH \& Chang MC 1964 The fertilizable life of ova and their morphology following delayed insemination in mature and immature mice. Journal of Experimental Zoology 155 237-251. (doi:10.1002/jez. 1401550211)

Mass DHA, Storey BT \& Mastroianni L 1976 Oxygen tension in the oviduct of the rhesus monkey (Macaca mulatta). Fertility and Sterility 27 1312-1317.

Mastroianni L \& Jones R 1965 Oxygen tension within the rabbit fallopian tube. Journal of Reproduction and Fertility 39 99-102.

Mayer W, Nivelelai A, Walter J, Fundele R \& Haaf T 2000 Demethylation of the zygotic paternal genome. Nature 403 501-502. (doi:10.1038/ 35000656)

Melov S, Coskun P, Patel M, Tuinstra R, Cottrell B, Jun AS, Zastawny TH, Dizdaroglu M, Goodman SI, Huang TT et al. 1999 Mitochondrial disease in superoxide dismutase 2 mutant mice. PNAS 96 846-851. (doi:10. 1073/pnas.96.3.846)

Miao Y, Liu X, Qiao T, Miao D, Luo M \& Tan J 2005 Cumulus cells accelerate aging of mouse oocytes. Biology of Reproduction 73 1025-1031. (doi:10.1095/biolreprod.105.043703)

Minami N, Suzuki T \& Tsukamoto S 2007 Zygotic gene activation and maternal factors in mammals. Journal of Reproduction and Development 53 707-715. (doi:10.1262/jrd.19029)

Monteiro HP, Ivanschenko Y, Fisher R \& Stern A 1991 Inhibition of protein tyrosine phosphatase activity by diamide is reversed by epidermal growth factor in fibroblasts. FEBS Letters 295 146-148. (doi:10.1016/00145793(91)81405-W)

Oikawa S, Hiraku Y, Fujiwara T, Saito I \& Kawanishi S 2002 Site-specific hydroxylation at polyguanosine in double-stranded DNA by nickel(II) in the presence of $\mathrm{SH}$ compounds: comparison with singlet oxygeninduced DNA damage. Chemical Research in Toxicology 15 1017-1022. (doi:10.1021/tx0101752)

Ono T, Mizutani E, Li C, Yamagata K \& Wakayama T 2011 Offspring from intracytoplasmic sperm injection of aged mouse oocytes treated with caffeine or MG132. Genesis 49 460-471. (doi:10.1002/dvg.20756)

Perez GI, Trbovich AM, Gosden RG \& Tilly JL 2000 Mitochondria and the death of oocytes. Nature 403 500-501. (doi:10.1038/35000651)

Perez GI, Juriscova A, Matikainen T, Morityama T, Kim MR, Takai Y, Pru JK, Kolesnick RN \& Tilly JL 2005 A central role for ceramide in the agerelated acceleration of apoptosis in the female germline. FASEB Journal 19 860-862. 
Qiao T, Liu N, Miao D, Zhang X, Han D, Ge L \& Tan J 2007 Cumulus cells accelerate aging of mouse oocytes by secreting a soluble factor(s). Molecular Reproduction and Development 75 521-528. (doi:10.1002/ mrd.20779)

Robak J \& Grygleweski RJ 1993 Nitric oxide donors as generators and scavengers of superoxide anion. Polish Journal of Pharmacology 45 51-58.

Rohn TT, Hinds TR \& Vincenzi FF 1993 lon transport ATPases as targets for free radical damage. Protection by an aminosteroid of the $\mathrm{Ca}^{2+}$ pump ATPase and $\mathrm{Na}^{+} / \mathrm{K}^{+}$pump ATPase of human red blood cell membranes. Biochemical Pharmacology 46 525-534. (doi:10.1016/0006-2952 (93)90530-A)

Schultz GA \& Heyner S 1992 Gene expression in pre-implantation mammalian embryos. Mutation Research 296 17-31. (doi:10.1016/ 0165-1110(92)90029-9)

Selby CP \& Sancar A 1990 Molecular mechanisms of DNA repair inhibition by caffeine. PNAS 87 3522-3525. (doi:10.1073/pnas.87.9.3522)

Shigenaga MK, Hagen TM \& Ames BN 1994 Oxidative damage and mitochondrial decay in aging. PNAS 91 10771-10778. (doi:10.1073/ pnas.91.23.10771)

Sohal RS \& Dubey A 1994 Mitochondrial oxidative damage, hydrogen peroxide release, and aging. Free Radical Biology \& Medicine 16 621-626. (doi:10.1016/0891-5849(94)90062-0)

Sont JK \& Vandenbroucke JP 1993 Life expectancy and mitochondrial DNA. Do we inherit longevity from our mother's mitochondria? Journal of Clinical Epidemiology 46 199-201. (doi:10.1016/0895-4356 (93)90058-9)

Spielmann H, Kruger C, Stauber M \& Vogel R 1985 Abnormal chromosome behavior in human oocytes which remained unfertilized during human in vitro fertilization. Journal of In Vitro Fertilization and Embryo Transfer 2 138-142. (doi:10.1007/BF01131500)

Sullivan SG, Chiu DT, Errasfa M, Wang JM, Qi JS \& Stern A 1994 Effects of $\mathrm{H}_{2} \mathrm{O}_{2}$ on protein tyrosine phosphatase activity in HER14 cells. Free Radical Biology \& Medicine 16 399-403. (doi:10.1016/0891-5849 (94)90042-6)

Sun Q, Miao Y \& Schatten H 2009 Towards a new understanding on the regulation of mammalian oocyte meiosis resumption. Cell Cycle $\mathbf{8}$ 2741-2747. (doi:10.4161/cc.8.17.9471)

Szollosi D 1971 Morphological changes in mouse eggs due to aging in the fallopian tube. American Journal of Anatomy 130 209-226. (doi:10.1002/aja.1001300207)

Takahashi T, Saito H, Hiroi M, Doi K \& Takahashi E 2000 Effects of aging on inositol 1,4,5-triphosphate-induced $\mathrm{Ca}^{2+}$ release in unfertilized mouse oocytes. Molecular Reproduction and Development 55 299-306. (doi:10.1002/(SICI)1098-2795(200003)55:3<299::AID-MRD8>3.0. CO;2-G)

Takahashi T, Takahashi E, Igarashi H, Tezuka N \& Kurachi H 2003 Impact of oxidative stress in aged mouse oocytes on calcium oscillations at fertilization. Molecular Reproduction and Development 66 143-152. (doi:10.1002/mrd.10341)

Takahashi E, Igarashi H, Kawagoe J, Amita M, Hara S \& Kurachi H 2009 Poor embryo development in mouse oocytes aged in vitro is associated with impaired calcium homeostasis. Biology of Reproduction 80 493-502. (doi:10.1095/biolreprod.108.072017)

Takai Y, Matikainen T, Juriscova A, Kim MR, Trbovich AM, Fujita E, Nakagawa T, Lemmers B, Flavell RA, Hakem R et al. 2007 Caspase-12 compensates for lack of caspase- 2 and caspase- 3 in female germ cells. Apoptosis 12 791-800. (doi:10.1007/s10495-006-0022-z)

Tamura H, Takasaki A, Miwa I, Taniguchi K, Maekawa R, Asada H, Taketani T, Matsuoka A, Yamagata Y, Shimamura K et al. 2008 Oxidative stress impairs oocyte quality and melatonin protects oocytes from free radical damage and improves fertilization rate. Journal of Pineal Research 44 280-287. (doi:10.1111/j.1600-079X.2007.00524.x)

Tarin JJ, Ten J, Vendrell FJ \& Cano A 1998 Dithtiothreitol prevents ageassociated decrease in oocyte/conceptus viability in vitro. Human Reproduction 13 381-386. (doi:10.1093/humrep/13.2.381)

Tarin JJ, Perez-Albala S, Aquilar A, Minarro J, Hermenegildo C \& Cano A 1999 Long-term effects of postovulatory aging of mouse oocytes on offspring: a two-generational study. Biology of Reproduction 61 1347-1355. (doi:10.1095/biolreprod61.5.1347)
Tarin JJ, Perez-Albala S \& Cano A 2000 Consequences on offspring of abnormal function in ageing gametes. Human Reproduction Update 6 532-549. (doi:10.1093/humupd/6.6.532)

Tarin JJ, Perez-Albala S, Perez-Hoyos P \& Cano A 2002 Postovulatory aging of oocytes decreases reproductive fitness and longevity of offspring. Biology of Reproduction 66 495-499. (doi:10.1095/biolreprod66.2.495)

Tatone C, Emidio GD, Barbaro R, Vento M, Ciriminna R \& Artini PG 2011 Effects of reproductive aging and postovulatory aging on the maintenance of biological competence after oocyte vitrification: insights from the mouse model. Theriogenology 76 864-873. (doi:10.1016/ j.theriogenology.2011.04.017)

Torres-Padilla ME, Bannister AJ, Hurd PJ, Kouzarides T \& ZernickaGoetz M 2006 Dynamic distribution of the replacement histone variant H3.3 in the mouse oocyte and preimplantation embryos. International Journal of Developmental Biology 50 455-461. (doi:10.1387/ijdb. 052073mt)

Wakayama S, Thuan NV, Kishigami S, Ohta H, Mizutani E, Hikichi T, Miyake M \& Wakayama T 2004 Production of offspring from one-day-old oocytes stored at room temperature. Journal of Reproduction and Development 50 627-637. (doi:10.1262/jrd.50.627)

Wang YA, Macaldowie A, Hayward I, Chambers GM \& Sullivan EA 2011 Assisted reproductive technology in Australia and New Zealand 2009, Assissted reproduction technology series no. 15. AlHW: Canberra, Australia.

Wesson DE \& Elliot SJ 1995 The $\mathrm{H}_{2} \mathrm{O}_{2}$-generating enzyme, xanthine oxidase, decreases luminal $\mathrm{Ca}^{2+}$ content of the $\mathrm{IP}_{3}$-sensitive $\mathrm{Ca}^{2+}$ store in vascular endothelial cells. Microcirculation 2 195-203. (doi:10.3109/ 10739689509146767)

Whatley SA, Curti D \& Marchbanks RM 1996 Mitochondrial involvement in schizophrenia and other functional psychoses. Neurochemical Research 21 995-1004. (doi:10.1007/BF02532409)

Wilcox AJ, Weinberg CR \& Baird DD 1998 Post-ovulatory ageing of the human oocyte and embryo failure. Human Reproduction 13 394-397. (doi:10.1093/humrep/13.2.394)

Wu Y, Wang X, Liu J, Bao Z, Tang D, Wu Y \& Zeng SM 2011 BIM EL-mediated apoptosis in cumulus cells contributes to degenerative changes in ages oocytes via a paracrine action. Theriogenology $\mathbf{7 6}$ 1487-1495. (doi:10.1016/j.theriogenology.2011.06.016)

Xu Z, Abbott A, Kopf GS, Schultz RM \& Ducibella T 1997 Spontaneous activation of ovulated mouse eggs: time-dependant effects on M-phase exit, cortical granule exocytosis, maternal messenger ribonucleic acid recruitment, and inositol 1,4,5-triphosphate sensitivity. Biology of Reproduction 57 743-750. (doi:10.1095/biolreprod57.4.743)

Yanagida K, Yazawa H, Katayose H, Suzuki K, Hoshi K \& Sato A 1998 Influence of oocyte preincubation time on fertilization after intracytoplasmic sperm injection. Human Reproduction 13 2223-2226. (doi:10.1093/humrep/13.8.2223)

Yoon SY, Jellerette T, Salicioni AM, Lee HC, Yoo MS, Coward K, Parrington J, Grow D, Cibelli JB, Visconti PE et al. 2008 Human sperm devoid of PLC, zeta 1 fail to induce $\mathrm{Ca}(2+)$ release and are unable to initiate the first step of embryo development. Journal of Clinical Investigation 118 3671-3681. (doi:10.1172/JCl36942)

Yoshida M, Ishigati K, Nagai T, Chikyu M \& Pursel VG 1993 Glutathione concentration during maturation and after fertilization in pig oocytes: relevance to the ability of oocytes to form male pronucleus. Biology of Reproduction 49 89-94. (doi:10.1095/biolreprod49.1.89)

Yu Y, Yong J, Li X, Qing T, Qin H, Xiong X, You J, Ding M \& Deng H 2005 The proteasomal inhibitor MG132 increases the efficiency of mouse embryo production after cloning by electrofusion. Reproduction 130 553-558. (doi:10.1530/rep.1.00758)

Zhang N, Wakai T \& Fissore RA 2011 Caffeine alleviates the deterioration of $\mathrm{Ca}(2+)$ release mechanisms and fragmentation of in vitro-aged mouse eggs. Molecular Reproduction and Development 78 684-701. (doi:10.1002/mrd.21366)

Received 20 March 2013

First decision 14 May 2013

Revised manuscript received 13 August 2013

Accepted 15 August 2013 